\title{
Uma espécie nova de Anthurium Schott (Araceae), endêmica na Serra da Bocaina, município de Bananal, São Paulo, Brasil
}

\author{
A new species of Anthurium Schott (Araceae), endemic \\ to Serra da Bocaina, Bananal municipality, São Paulo, Brazil
}

Eduardo Luís Martins Catharino ${ }^{1} \&$ Marcus A. Nadruz Coelho ${ }^{2}$

\begin{abstract}
Resumo
Uma espécie nova do gênero Anthurium, de endemismo restrito, é descrita para o município de Bananal no estado de São Paulo. Anthurium tomasiae pertence à seção Urospadix subseçãoFlavescentiviridia e é endêmica da Serra da Bocaina, bioma Mata Atlântica, em áreas úmidas e rochosas. É fornecida diagnose, ilustração e comentários acerca da distribuição geográfica, ecologia, registro de floração, frutificação e conservação para a espécie.

Palavras-chave: Anthurium, Mata Atlântica, nova espécie, taxonomia.
\end{abstract}

\begin{abstract}
A new narrowly endemic species of the genus Anthurium is described from Bananal municipality in the state of São Paulo. Anthurium tomasiae is endemic to Serra da Bocaina, and belongs to section Urospadix subsection Flavescentiviridia. The species occurs in the Atlantic rain forest biome in humid rocky areas. Description and illustrations are provided together with commentary on geographic distribution, ecology, flowering and fruit phenology and conservation status.

Key words: Anthurium, Atlantic rain forest, new species, taxonomy.
\end{abstract}

\section{Introdução}

O gênero neotropical Anthurium Schott, com aproximadamente 1100 espécies, situa-se na subfamília Anthurieae, tribo Potheae, (Coelho 2009). As espécies estão distribuídas do norte do México e das Grandes Antilhas ao sul do Brasil e norte da Argentina e Uruguai, nas baixas e médias elevações, com maior diversidade no Panamá, Colômbia e Equador (Mayo et al. 1997; Carroll 2003). No Brasil ocorre em todas as regiões, com cerca de 110 espécies (Temponi 2007).

Atualmente o gênero Anthurium está subdividido em 19 seções (Croat 1983; Keating 2002). A seção Urospadix, composta de sete subseções, foi descrita por Engler (1878) e suas espécies estão concentradas no Brasil leste e sudeste (Coelho 2009). Nos últimos anos várias espécies novas do gênero têm sido descritas para o sudeste brasileiro, sendo sete delas de ocorrência no estado de São Paulo: Anthurium jureianum (Catharino \& Olaio 1990); A. bocainense e A. ameliae (Coelho \& Catharino 2005), A. victorii e A. unense (Coelho 2006) e A. navicularis e $A$. alcatrazense (Coelho \& Catharino 2008).

A Serra da Bocaina localiza-se no maciço da Serra do Mar, entre os estados do Rio de Janeiro e São Paulo, constituindo-se uma das regiões de especial diversidade da Mata Atlântica. Esta rica região na costa do Atlântico apresenta paisagens montanhosas e escarpadas, planícies, costões e praias litorâneas propiciando uma grande diversidade de espécies vegetais, em parte protegidas por Unidades de Conservação, em especial o Parque Nacional da Serra da Bocaina,

'Instituto de Botânica de São Paulo, Av. Miguel Stefano, São Paulo, SP, Brasil. mcatarin@uol.com.br

${ }^{2}$ Instituto de Pesquisas Jardim Botânico do Rio de Janeiro, R. Pacheco Leão 915, 22460-030, Rio de Janeiro, RJ, Brasil. 
nos limites dos dois estados. Espécies novas de várias famílias botânicas têm sido coletadas na região, inclusive duas espécies de Anthurium, também endêmicas, descritas recentemente (Coelho \& Catharino 2005).

Anthurium tomasiae, por ser uma espécie de ocorrência muito restrita e com populações pequenas, além das incertezas sobre a efetiva conservação, em vista dos poucos registros de coleta, e da importante área natural em que ocorre, provavelmente fora de Unidade de Conservação, pode ser considerada vulnerável ou em risco de extinção pelos critérios da IUCN (2003).

Anthurium tomasiae Catharino \& Nadruz, sp. nov. Tipo: BRASIL. SÃO PAULO: Bananal. Sobre folhedo em áreas rochosas no entorno do Rio Bracuhy, Serra da Bocaina. 15.XII.2006, E.L.M. Catharino et al. 2790 (holótipo SP!; isótipo RB!).

Fig. 1

Anthurium tomasiae Catharino et Nadruz sp. nov., Anthurio longicuspidato Engler affine, sed caule decumbenti, internodiis et spadicis stipite longioribus, spatha naviculari differt.

Caule fino, decumbente; entrenós 1,5-4,6 cm compr.; profilos e catafilos inteiros no ápice, inteiros a levemente decompostos para a base do caule, persistentes, acastanhados, 1,5-2,5 cm compr.; pecíolo cilíndrico abaxialmente, levemente sulcado adaxialmente, esverdeado, ereto, 6-11,3 cm compr.; genículo intumescido, 0,6-1 cm compr.; lâmina foliar esverdeada, discolor, membranácea em material seco, subovada a lanceolada, ápice rostrado, base arredondada a truncada, 10,1-11,2 ×2,2-3,6 cm; nervura primária sem observação da seção transversal; nervuras secundárias visíveis em ambas as faces em material seco, 5-8 em ambos os lados; nervura coletora partindo da base da lâmina distante $0,4 \mathrm{~cm}$ da margem; pedúnculo cilíndrico, esverdeado, ereto, 9,2-16 cm compr.; espata membranácea, linearlanceolada, esverdeada, navicular, em pré-antese e antese com cerca de $45^{\circ}$ em relação ao estípite, formando ângulo reto com o pedúnculo, 1,6-2,2 cm compr.; espádice subcônico, esverdeado, longamente estipitado, 2,1-2,4 cm compr., estípite 4-6,8 cm compr.; flores 2 na espiral primária e 4 na secundária, tépalas cuculadas, anteriores/posteriores côncavas ventralmente e subcarenadas dorsalmente, as laterais levemente côncavas ventralmente e subcarenadas dorsalmente, androceu com 4 estames; frutos bagas, imaturos esverdeados.
Material examinado: SÃO PAULO: Bananal, Serra da Bocaina, Rio Bracuhy, VI.2006, E.L.M. Catharino\& M. Nadruz 2798 (SP).

Erva rupícola, higrófila e heliófila. Ocorre em locais de altíssima umidade atmosférica, estando sujeita aos constantes respingos de água, dessecando rapidamente quando retirada do hábitat. Caracteriza-se, principalmente, pela presença de estípite longo (até 6,8 cm compr.), caráter esse não encontrado na maioria das espécies. Anthurium tomasiae pertence à seção Urospadix subseção Flavescentiridia por apresentar lâmina foliar membranácea, discolor, com base obtusa a truncada, nervuras secundárias visíveis e mais proeminentes do que as terciárias, com ocorrência no sudeste do Brasil, conhecida apenas através da coleção-tipo oriunda do Estado de São Paulo, próximo à divisa com o Rio de Janeiro. Pode ser confundida com A. longicuspisdatum Engler, que difere por apresentar caule ereto, entrenós abaixo de 1,5 cm compr., estípite ausente e espata aplanada.

O epíteto específico faz menção à ilustradora botânica Maria Cecília Tomasi, que ilustra a espécie aqui descrita, para a qual prestamos esta homenagem, em agradecimento a sua contribuição para o estudo da flora brasileira, com suas precisas e belas ilustrações botânicas.

\section{Referências}

Catharino, E.L.M. \& Olaio, A. 1990. Anthurium jureianum Catharino \& Olaio, nova espécie para o litoral paulista. Hoehnea 17: 1-6.

Carroll, N. 2003. The Anthurium primer. Disponível em $<$ http://www.aroid.org/TAP/TAPstructure.html>. Acesso em 8 outubro 2009.

Coelho, M.A.C. 2006. New species of Anthurium (Araceae) from Brazil. Aroideana 29: 91-103.

Coelho, M.A.C. \& Catharino, E.L.M. 2005. Duas espécies novas de Anthurium Schott (Araceae) para o Brasil. Rodriguésia 56: 35-41.

Coelho, M.A.C. \& Catharino, E.L.M. 2008. Duas espécies novas de Anthurium (Araceae) endêmicas do litoral de São Paulo. Rodriguésia 59: 829-833.

Croat, T.B. 1983. A revision of the genus Anthurium (Araceae) of Mexico and Central America. Part 1: Mexico and Central America. Annals of the Missouri Botanical Garden 70: 211-417.

Coelho, M.A.N.; Waechter, J.L. \& Mayo, S.J. 2009. Revisão taxonômica das espécies de Anthurium (Araceae) seção Urospadix subseção Flavescentiviridia). Rodriguésia 60: 799-864.

Engler, A. 1878. Araceae. In: Martius, C.F.P. Flora brasiliensis. Vol. 3, pars 2. Pp. 56-88, tab. 11-102. 


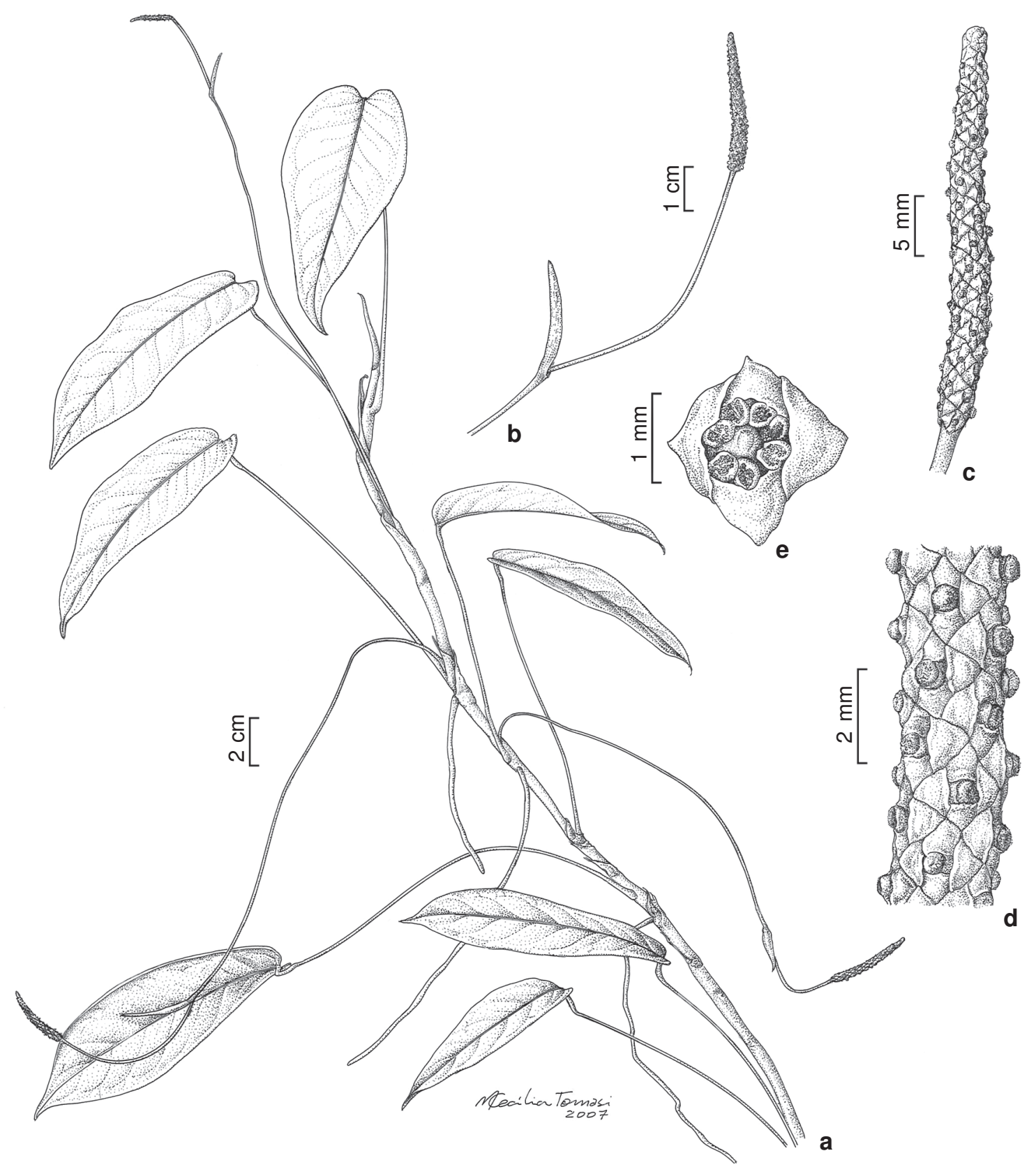

Figura 1 - Anthurium tomasiae Catharino \& Nadruz - a. ramo florífero; b. inflorescência: espata e espádice; c. espádice; d. detalhe do espádice; e. flor em vista frontal (a-e Catharino \& Nadruz 2798).

Figure 1 - Anthurium tomasiae Catharino \& Nadruz-a. flowering branch; b. inflorescence: spathe and spadix; d. spadix in detail; e. flower, frontal view (a-e Catharino \& Nadruz 2798). 
IUCN. 2003. Red list of threatened species. Disponível em $<$ http://www.iucn.org/themes/ssc/redlists/RLcats2001 booklet.html>. Acesso em 8 outubro 2009.

Keating, R.C. 2002. Anatomy of the monocotyledons IX. Acoraceae and Araceae. Clarendon Press, Oxford. 322p. il.
Mayo, S.J.; Bogner, J. \& Boyce, P.C. 1997. The genera of Araceae. Royal Botanic Garden, Kew. 370pp. il.

Temponi, L.G. 2007. Sistemática de Anthurium seção Urospadix (Araceae). Tese de Doutorado. Universidade de São Paulo, São Paulo. 143p.

Artigo recebido em 15/10/2009. Aceito para publicação em 22/03/2010. 